\title{
Shifting from Face-to-Face to Online Teaching During COVID-19: The Role of University Faculty Achievement Goals for Attitudes Towards This Sudden Change, and Their Relevance for Burnout/Engagement and Student Evaluations of Teaching Quality
}

\author{
Martin Daumiller \\ University of Augsburg \\ Stefan Janke \\ University of Mannheim
}

\author{
Raven Rinas \\ University of Augsburg \\ Oliver Dickhäuser \\ University of Mannheim
}

\author{
Julia Hein \\ University of Mannheim \\ Markus Dresel \\ University of Augsburg
}

\begin{abstract}
As a result of the COVID-19 pandemic, many faculty members were required to abruptly shift from face-to-face to online teaching. Within this, some instructors managed well, while others struggled. To elucidate interindividual differences in online teaching and learning during this unexpected circumstance, we focus on faculty members' attitudes towards this shift and examine their associations with underlying motivations as well as burnout/engagement and student learning. We analyzed longitudinal data of 80 faculty members' achievement goals during the semester prior to shifting to online teaching, as well as their attitudes and burnout/engagement during the first semester with enforced online teaching. We additionally included 703 student ratings of these faculty members' teaching quality. Results indicated that learning approach goals of faculty were positively associated with perceiving the shift to online teaching as a positive challenge and as useful for their own competence development. Conversely, performance (appearance) avoidance and work avoidance goals went along with perceiving this change as threatening, which was in turn positively related to burnout levels and negatively related to student ratings of teaching quality. Taken together, these findings point to the relevance of faculty goals and attitudes for successful online teaching and learning.
\end{abstract}

Keywords: teacher, motivation, goal orientations, attitudes, corona, stress

(C) 2021, Elsevier. The official citation for this manuscript is: Daumiller, M., Rinas, R., Hein, J., Janke, S., Dickhäuser, O., \& Dresel, M. (2021). Shifting from face-to-face to online teaching during COVID-19: The role of university faculty achievement goals for attitudes towards this sudden change, and their relevance for burnout/engagement and student evaluations of teaching quality. Computers in Human Behavior. Advanced online publication. https://doi.org/10.1016/j.chb.2020.106677. This paper is not the copy of record and may not exactly replicate the final, authoritative version of the article. The final article will be available, upon publication, via its DOI.

As a result of the COVID-19 pandemic, many faculty members were required to abruptly shift from faceto-face to online teaching. Consequently, some struggled and experienced hurdles and high stress levels, while others perceived this sudden shift to be a positive

Correspondence concerning this article should be addressed to Martin Daumiller, Department of Psychology, University of Augsburg, Universitätsstr. 10, 86159 Augsburg, Germany; Martin.Daumiller@phil.uni-augasburg.de.

We have no known conflicts of interest to disclose.

The research reported in this article was supported by the German Research Foundation (Deutsche Forschungsgemeinschaft; DFG): Grant DR 454/8-1 awarded to Markus Dresel and Grant DI 929/5-1 awarded to Oliver Dickhäuser. opportunity, managed to cope well, and facilitated positive learning activities for their students (Bhat et al., 2020; Ortiz, 2020). This COVID-19 induced shift to online teaching constitutes a clear achievement situation in that for many faculty members, it marked the first time that it was mandatory for all courses to be exclusively taught online, thereby entailing a relevant learning and qualification situation where it was simultaneously important to perform well and successfully support students. As such, COVID-19 can be seen as a natural paradigm that accentuates interindividual differences in the achievement context of how faculty experience and handle online teaching and learning. While much is known about digital technologies in ed- 
ucational contexts, investigations into personal prerequisites of faculty are especially helpful to better understand differences in the academic practice of online teaching and learning (see Hofer, Nistor, \& Scheibenzuber, this special issue; Martin et al., 2020). Specifically, investigating faculty attitudes towards the shift to online teaching as well as their motivational underpinnings can meaningfully illuminate interindividual differences regarding the implementation of online technologies in higher education teaching and how this can be better supported.

From a psychological perspective, faculty members' attitudes towards this unexpected challenge can be considered relevant for how they experience and handle the enforced online teaching situation. This notion is illustrated in the integrative digital teaching and learning framework developed by Sailer, Schultz-Pernice, and Fischer ( $\mathrm{Cb}$-model; this special issue). Therein, the authors highlight faculty attitudes concerning digital technology (along with their digital and technology-related skills) as a central personal factor that is both related to the experiences of faculty during this academic qualification, and, through their use of digital technology in teaching, their students' learning. In line with this framework, we considered faculty burnout experiences and student evaluations of teaching quality in terms of learning as two relevant outcomes that should be related to interindividual differences in the attitudes towards this shift to online teaching.

Based on faculty having different attitudes towards this sudden shift to online teaching, understanding how they can be traced back to different motivations is particularly important. Thus, as a prominent framework for the study of faculty motivation that focuses on the value-part of motivation, we examined their achievement goals (for an overview see Daumiller, Stupnisky, et al., 2020). Theoretically it can be expected that the abrupt challenge of shifting to online teaching is perceived differently depending on faculty members' goals. For example, the shift may be perceived as useful for faculty members with strong strivings to improve their competences and learn something new, while for those who are concerned about performing poorly, it might be perceived as more threatening.

Taken together, in the present work, we investigated the role of faculty members' achievement goals for their attitudes towards dealing with the shift to online teaching during COVID-19, and how these attitudes were in turn associated with their burnout/engagement experiences as well as students' evaluations of teaching quality in terms of learning.

\subsection{Shifting from Face-to-Face to Online Teaching: An Unexpected Challenge}

Digital technologies for education have substantially changed instructional practices in higher education over the past decades (Sailer et al., this special issue). This means that digital technology should not be unfamiliar to educational practitioners in higher education. Nevertheless, prior to COVID-19, teaching in higher education was carried out predominantly in face-to-face formats, enriched with digital technologies on an occasional basis at best. While a transition from face-to-face to blended, online, or flipped classroom teaching requires careful planning, this was not possible during the onset of the COVID-19 crisis due to the unprecedented physical closing of universities and schools in most countries (UNESCO, 2020). The physical closing of educational institutions temporarily enforced a sudden transition that accelerated the digitalization of teaching. Consequently, faculty-holding a key role in online teaching alongside students' learning activities, as well as the administrative/university environment (Sailer et al., this special issue) -were confronted with the unexpected challenge of teaching exclusively online. In doing so, they experienced many hurdles (see Damşa \& Langford, this special issue) centered around the need to re-design teaching activities for their students, coupled with frustration, fear, uncertainty, challenges in time management and sustaining students' interest, a rise in cheating on examinations/quizzes, and difficulties in maintaining a healthy work-life-balance (Ahmed et al., 2020). Against this background, COVID-19 can be considered a stress test as well as a booster of online teaching and learning.

Considering this, it needs to be borne in mind that faculty often have to deal with unexpected challenges, particularly as educational programs constantly change (e.g., bologna process, see Zahavi \& Friedman, 2019). Reasons for such changes may be due to political decisions, learning and technological innovations, inequality of educational programs, or discontinuation of financing (see also Maloney \& Kim, 2020; Sălceanu, 2020). The situation that we analyze within our study is particularly noteworthy, as the period of change was exceptionally short within the sudden close of universities due to COVID-19. Thus, on a more general note, investigating faculty members' attitudes surrounding this unexpected shift to online teaching can be considered an important research avenue to gain insights into how they experience such challenges and how to support them in mastering these challenges. 


\subsection{Attitudes Towards the Sudden Shift to Online Teaching}

Different attitudes are thought to arise from the ways in which individuals appraise challenges (Schwarzer \& Jerusalem, 1995), including those associated with the shift to online teaching and learning during COVID-19. Similar to students (see Reinhold et al., this special issue), we assume that teachers' attitudes towards this shift are paramount in understanding interindividual differences in how faculty experience and respond to this situation. More specifically, based on prior investigations into attitudes towards challenging work situations and new teaching targets (e.g., Gorozidis \& Papaioannou, 2011; Krischler \& Pitten Cate, 2019), we distinguish between three types of attitudes: perceived threat (e.g., being concerned about problems that could arise from the shift from face-toface to online teaching), perceived usefulness for competence development (e.g., finding the shift helpful to learn and increase professional competences), and perceived positive challenge (e.g., experiencing feelings of confidence and capability concerning meeting the demands tied to the shift).

Indeed, prior research has indicated that attitudes towards technology are highly relevant for technological experiences (e.g., Technology Acceptance Model; Davis, 1985; Dwivedi et al., 2017; Venkatesh \& Davis, 2000; cf. Nistor \& Wagner, 2010; Venkatesh et al., 2003), including those presented in educational contexts (see Hernández-Ramos et al., 2014). In the present work, we focus on superordinate personal attitudes towards the shift to online teaching instead of attitudes concerning the use of specific types of technology. In particular, the types of attitudes that we focus on have also been successfully studied in the field of achievement goal research where they have been postulated as a consequence of the different types of goals that individuals pursue (e.g., Butler, 2007; Daumiller et al., 2019; Dickhäuser, et al., 2007; Huet et al., 2011; Ryan \& Pintrich, 1997; Tanaka et al., 2002).

\subsection{Faculty Achievement Goals as Motivational Underpinnings of Different Attitudes Towards the Shift to Online Teaching}

Within the research on teacher and faculty motivation, the achievement goal approach is a prominent framework (Butler, 2007; Daumiller et al., 2016, 2019). Achievement goals describe competence-related sets of goals that individuals pursue to different strengths and for which different cognitive, behavioral, and affective consequences have been documented (Hulleman et al., 2010). The most prominent model in this line of research distinguishes between learning approach (e.g., striving to develop competence), performance approach (e.g., striving to be perceived as competent), performance avoidance (e.g., striving to avoid appearing incompetent), and work avoidance (e.g., striving to get through the day with little effort) goals (see Butler, 2014). First studies have documented associations between these achievement goals and faculty members' professional learning, stress experiences, and attitudes (see Daumiller, Stupnisky, et al., 2020, for an overview). ${ }^{1}$ Theoretically, achievement goals represent the end-states that individuals strive for. As motivational orientations, they are posited to shape perceptions of achievement situations and underlie different interpretations regarding the purpose and meaning that individuals ascribe to such situations. Particularly, quantitative and qualitative evaluations of the constituents of a given situation (i.e., attitudes regarding these constituents) are theoretically apparent consequences of these motivational orientations. Therefore, achievement goals can be expected to give rise to different attitudes of faculty towards the unexpected shift to online teaching during COVID-19.

Specifically, faculty with strong learning goals can be expected to perceive this unexpected challenge of online teaching more strongly as a situation that may provide grounds to improve competences and, in consequence, be interpreted as a learning opportunity instead of self-threatening. As such, learning approach goals can be presumed to be related to perceiving this challenge as non-threatening, as a positive challenge, and as useful for competence development. This notion has been supported by positive links between students' and teachers' learning goals and perceiving help-seeking as less threatening and useful (Butler, 2007; Daumiller et al., 2019; Dickhäuser, et al., 2007; Huet et al., 2011; Ryan \& Pintrich, 1997; Tanaka et al., 2002), teachers' attitudes towards implementing a new curricula (Gorozidis \& Papaioannou, 2011), and students perceiving desirable difficulties more positively (Weissgerber et al., 2016).

As described above, the shift from face-to-face to digital teaching also constituted a performance situation for faculty in that how they handled this situation became quite visible to their students. Given this background, faculty members with strong performance approach goals might interpret this as a stimulating opportunity that can be used to make a good impression. Aside from this, we had no directional expectations for perceived threat and perceived positive challenge 
(which is also in line with the often-found nil associations concerning performance approach goals and attitudes towards help-seeking; see, for example, Tanaka et al., 2002).

In contrast, faculty members with strong performance avoidance goals can be expected to perceive such challenges as self-threatening, negative, and not particularly useful, as they seek to avoid being perceived as incompetent - analogous to studies that have found these goals to be associated with perceiving helpseeking as threatening (e.g., Dickhäuser, et al., 2007; Skaalvik \& Skaalvik, 2005; see also Karabenick, 2004, and Linnenbrink, 2005, for similar findings in students). Therefore, unfavorable associations between performance avoidance goals and attitudes towards the shift to online teaching seem likely.

Similarly, unfavorable associations can also be expected for work avoidance goals. Given that individuals with strong work avoidance goals seek to refrain from investing too many resources and putting forth too much effort, they can be presumed to perceive the COVID-19 induced shift to online teaching and the additional work and changes required to deal with this situation as more threatening, negative, and not useful (Daumiller et al., 2019; Dickhäuser, et al., 2007).

\subsection{Faculty Burnout/Engagement and Student Evaluations of Teaching Quality as Relevant Outcomes in Online Teaching and Learning}

We expect faculty attitudes and achievement goals to underlie interindividual differences in how they experience and react to this shift to online teaching and learning in the wake of the COVID-19 pandemic - an achievement situation that is characterized by both learning and performance. Specifically, these personal aspects can be presumed to be related to their experiences during this qualification phase and, through their teaching behaviors, also their students' learning activities (see also Sailer et al., this special issue).

Regarding faculty experiences, COVID-19 has elicited considerable feelings of stress and strain while adapting to online teaching and learning (Besser et al., 2020). Whether these experiences impact faculty wellbeing, depends on their construal of this distress (see Sabagh et al., 2018, for an overview). Here, achievement goals and attitudes can be regarded as resources or determinants of individuals' primary and secondary appraisals of stressors, and as such, matter for the manifestation of stress (Folkman et al., 1986; see Daumiller \& Dresel, 2020). The latter is commonly described with the concept of "burnout" (Freudenberger, 1974) that is understood as an erosion of occupational engagement (Maslach \& Leiter, 2008) and constitutes a continuum running from a positive pole (engagement) to a negative pole (burnout) of handling work situations. It includes emotional exhaustion (feeling depleted and no longer interested in one's occupation), cynicism (a distanced attitude to work in general), and reduced personal accomplishment (experiencing limited performance and a reduced meaningfulness of one's work). Against this background, learning goals and perceiving the current situation as non-threatening, as a positive challenge, and as useful for competence development, should go along with perceiving teaching and learning during COVID-19 as more positive and controllable, and consequently, with reduced burnout levels. Conversely, performance avoidance and work avoidance goals, as well as strongly perceiving the situation as threatening, not as a positive challenge, and of little usefulness, can be expected to be associated with increased concern, less successful coping, limited resources, and as such, increased burnout levels.

Furthermore, following the overview model by Sailer et al. (this special issue), we expect faculty attitudes towards this shift to also matter for teaching practice, and consequently, students' evaluations of teaching quality in terms of learning. By perceiving the online teaching situation as threatening, faculty members can be presumed to hold back and not fully exploit its potential, for example, by limiting themselves to teaching in the form of safer (more controllable) and less resource-intensive passive learning activities instead of more constructive and interactive learning activities that could support better learning (e.g., Chi \& Wylie, 2014; Wekerle et al., 2020). In particular, faculty members might set out to do more asynchronous instead of synchronous teaching, which is frequently considered less effective due to the reduced interaction level between faculty members and students (Offir et al., 2008). The opposite can be expected for perceptions of this situation as a positive challenge and as being useful for their own competence development, which should therefore be facilitative of improved student learning. Given that students' learning activities are rather complex and difficult to compare across different teachers and subjects, we focus our investigation on student learning as a product factor of teaching quality (Marsh, 1982, 2007). Shared student ratings can thereby serve as a proxy for how well their instructor managed to provide meaningful and high-quality learning activities for them. 


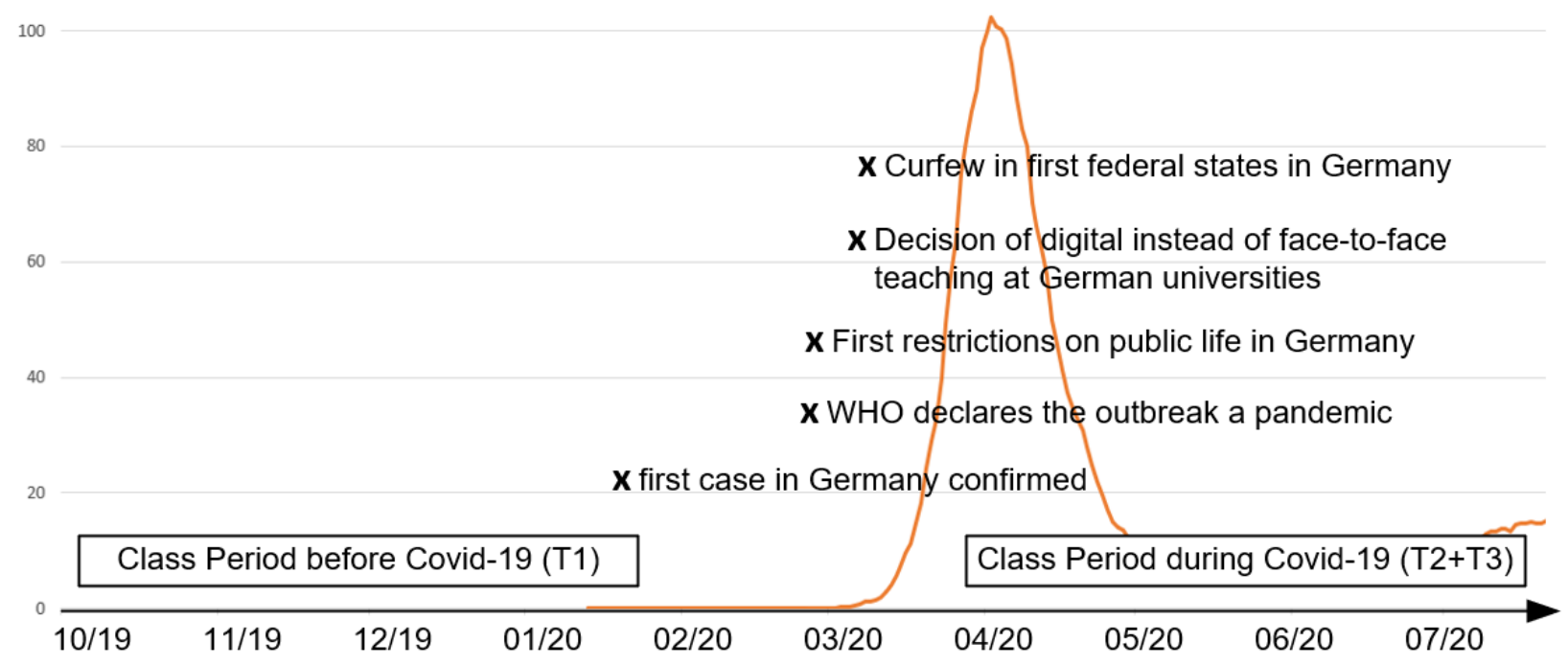

Figure 1. Overview of the COVID-19 outbreak, measures and policy changes, and infected cases (cumulative number for 14 days of confirmed COVID-19 cases per 100000) in Germany that led to the summer semester being taught online instead of face-to-face.

\subsection{The Present Research and Hypotheses}

We investigated how faculty members' motivations are associated with interindividual differences in their handling of the unexpected challenge of shifting from face-to-face to online teaching. In light of the COVID19 outbreak and the subsequent forced transition to online teaching, our study uses a natural paradigm to investigate this. Specifically, we focus on how faculty achievement goals prior to this shift are associated with subsequent interindividual differences in their attitudes towards the shift, and how these attitudes are in turn related to faculty members' burnout/engagement and their students' assessments of teaching quality in terms of learning. Based on the theoretical and empirical background provided above, we hypothesized the following:

(Hypothesis H1a) Learning approach goals are positively associated with perceived positive challenge and perceived usefulness, and negatively associated with perceived threat.

(Hypothesis H1b) Performance approach goals are positively associated with perceived positive challenge.

(Hypothesis H1c) Performance avoidance goals are negatively associated with perceived positive challenge and perceived usefulness, and positively associated with perceived threat.

(Hypothesis H1d) Work avoidance goals are negatively associated with perceived positive challenge and perceived usefulness, and positively associated with perceived threat.
(Hypothesis H2a) Perceived positive challenge and perceived usefulness are negatively and perceived threat is positively associated with faculty burnout levels.

(Hypothesis H2b) Perceived positive challenge and perceived usefulness are positively and perceived threat is negatively associated with students' evaluations of teaching quality.

In particular, we expected that faculty goals are associated with burnout/engagement and teaching quality mediated through their attitudes.

\section{Material and Methods}

We used data from a larger longitudinal study that was interrupted by the COVID-19 outbreak (Daumiller, Janke et al., 2021). In each semester of this study, for a total of three semesters, faculty were asked to complete a questionnaire regarding their personal experiences, and subsequently, their students were invited to fill out a questionnaire assessing teaching quality. For the present study, we used data on faculty motivation from the semester prior to the COVID-19 induced shift from face-to-face to online teaching, and faculty attitudes, their experienced burnout/engagement, as well as students' evaluations of teaching quality in terms of learning in the first semester of enforced online teaching after the COVID-19 outbreak (see Figure 1 for an overview). 


\subsection{Sample}

A total of 114 faculty members participated in both measurement points. Out of these, 80 stated that their teaching changed from face-to-face to online teaching, while the remaining participants either answered that all of their classes were cancelled this semester or that they had a teaching-free semester, which is why we excluded them. Our final sample therefore consisted of 80 faculty members (at T1: 46 male, 33 female, 1 diverse; average age: 29.3, $\operatorname{Min}=24, \operatorname{Max}=65, S D=10.0$, years; average teaching experience: 9.86, $\operatorname{Min}=1$, Max $=36, S D=8.0$, years; 28 faculty members without $\mathrm{PhD}, 44$ faculty members with $\mathrm{PhD}, 8$ full professors; 23 tenured, 57 untenured). ${ }^{2}$ All of the participants taught at German universities. Most of the participants had no or little experience with online teaching $(80.4 \%)$, while only few stated that they had frequently used online teaching before $(19.6 \%) .{ }^{3}$ The online teaching quality of these faculty members during COVID-19 was evaluated through ratings of 703 students attending their courses.

\subsection{Measures}

We measured achievement goals for teaching in the semester prior to the COVID-19 transition to online teaching. Additionally, in the first semester of enforced online teaching, the participants reported their attitudes towards the transition to online learning and their burnout/engagement. About one month following this, students provided ratings of teaching quality in terms of learning. We labelled these measurement points as T1 for the faculty assessments before shifting to online teaching, T2 for the faculty assessments afterwards, and T3 for the subsequent student assessments.

\subsubsection{Faculty Achievement Goals for Teaching}

We used the university instructor achievement goal questionnaire by Daumiller et al. (2019). With regard to their teaching activities, participants assessed their learning approach (e.g., "I want to constantly improve my competences"; $\omega=.95$ ), performance (appearance) approach (e.g., "I want to be perceived as competent"; $\omega=.90$ ), performance (appearance) avoidance (e.g., "I want to avoid being perceived as incompetent"; $\omega=.94$ ), and work avoidance goals (e.g., "I want to have as little to do as possible"; $\omega=.95$ ) on Likert-type scales ranging from 1 (do not agree at all) to 8 (agree completely). ${ }^{4}$ Confirmatory factor analyses confirmed the structure and reliability of these four goal types $(\mathrm{CFI}=.98, \mathrm{TLI}=.97, \mathrm{SRMR}=.08)$.

\subsubsection{Faculty Attitudes Towards the Change to Online Teaching}

We modified existing scales and referred them to the COVID-19 enforced change from face-to-face to online teaching. With regard to this sudden change, participants reported how strongly they experienced it as a threat, a positive challenge, and as useful for their own competence development. We used three items based on Schwarzer and Jerusalem (1995) to measure perceived threat (e.g.,"I am worried about the problems that might occur to me because of this change in teaching"; $\omega=.71$ ), three items based on a scale of Jerusalem (1995; cited in Schwarzer \& Jerusalem, 1999) to assess perceived positive challenge (e.g., "I like the challenges I face as a result of this change to online teaching"; $\omega=.84$ ), and three items based on Dickhäuser et al. (2007) to assess perceived usefulness for competence development (e.g., "I find this change in teaching to be an interesting opportunity to gain new experiences"; $\omega=.87)$. All items were answered on Likerttype scales ranging from 1 (do not agree at all) to 8 (agree completely). Confirmatory factor analyses confirmed the structure and reliability of these three attitudes $(\mathrm{CFI}=.96, \mathrm{TLI}=.94, \mathrm{SRMR}=.07)$.

\subsubsection{Faculty Burnout/Engagement}

We used the German translation of the Maslach Burnout Inventory for Educators (Büssing \& Glaser, 1998; Daumiller \& Dresel, 2018). It encompasses (a) emotional exhaustion (e.g., "I feel emotionally exhausted by my work"; 9 items; $\omega=.90$ ), (b) cynicism (e.g., "I just want to do my job and be left alone"; 5 items; $\omega=.74$ ), and (c) reduced personal accomplishment (e.g., "I feel good when I have achieved something at work"; 8 items; $\omega=.78$ ). The last eight items reflect positive engagement and were reverse coded for the analyses; therefore, high values represent a strongly perceived lack of personal accomplishment. Overall, high scores indicate burnout, and low scores reflect engagement. The participants were requested to state on a Likert scale ranging from 1 (never) to 7 (always [daily]) how often they experienced the presented aspects in their current work. As we were interested in burnout/engagement as a whole, we analyzed it on the overall scale level by averaging the three subaspects to form a uniform indicator of burnout/engagement 
$(\omega=.83$; in line with prior research, see Brenninkmeijer \& van Yperen, 2003; Daumiller \& Dresel, 2020; and additionally justified by sufficiently large loadings of these subaspects to a second-order factor reflecting general burnout/engagement levels: $\lambda=.35-.78$ ).

\subsubsection{Student Evaluations of Teaching Quality in Terms of Learning}

We assessed student learning in the form of the respective product factor of teaching quality using a German translation of the SEEQ (Marsh, 1982, 2007; Daumiller, Grassinger et al., 2021). Students assessed teaching quality in terms of learning with five items (e.g., "I have learned a lot in this course"; $\omega=.84$ ) that were to be answered on a Likert-type scale ranging from 1 (do not agree at all) to 5 (agree completely). The scale had an additional answer option "not applicable" that we treated as missing data. The scale had good to very good reliability on the teacher level (assessments of individual students regarding their instructors' teaching; ICC2 $=.87$ ). Through two-level modelling, we extracted the shared student assessments (between part) to yield a teacher-specific score reflecting the shared ratings of their students that we used in our analyses.

\subsection{Missing Data and Power Analysis}

There were little missing values for participants' achievement goals and their burnout/engagement ( $<5 \%$ for each item; $<3.7 \%$ on the scale level). However, there were large portions of missing data for participants' attitudes (55\%) and students' evaluations of teaching quality (50\%). The missing data in the attitudes was due to a technical issue in the survey, due to which, unsystematically, half of the participants were not presented with these items. This can therefore be considered missing completely at random. Sources of missingness in student evaluations entail, for example, students not having been provided with an invitation to evaluate their teachers (we asked teachers to either provide us with the email addresses of the students or to forward the survey link to them). To confirm that both missingness in student evaluations and missingness in attitudes were not systematically related to any of the assessed teacher variables, we conducted multiple $t$ tests (comparing those with missing student evaluations respectively with responses for their attitudes against those without), none of which were statistically significant (all $p>.10$; furthermore, all mean differences were descriptively very small). All missing data was handled using the full-information maximum likelihood estimation (FIML) and the expectation maximization (EM)-algorithm for the analyses, which has been shown to produce unbiased parameter estimates and standard errors for data missing at random (Enders \& Bandalos, 2001; Peugh \& Enders, 2004; see Little et al., 2016).

To confirm that the sample size and the amount of missing data was adequate for our investigation, we conducted power tests. Monte Carlo simulation analyses assuming medium effects and missing data patterns as described above showed that the given sample size was adequate to confirm $\mathrm{H} 1$ (attitudes regressed on attitudes) with a power of .82, $\mathrm{H} 2 \mathrm{a}$ (burnout/engagement regressed on attitudes) with a power of .89. Only for $\mathrm{H} 2 \mathrm{~b}$ (teaching quality regressed on attitudes) with a power of .75 did the value fall slightly short of the often used criterion of .80. Overall, the data basis can therefore be considered adequate to investigate our research questions, however it should be borne in mind that it may not be sufficient for detecting small effects, particularly with regard to the student evaluations.

\subsection{Analyses}

To test the hypotheses, we estimated a path model in Mplus 8.1 (Muthén \& Muthén, 2018) using MLR as an estimator to control for not all variables being normally distributed. We regressed burnout/engagement and teaching quality on the three attitudes that were in turn regressed on the four achievement goals. Correlations between achievement goals and between attitudes were allowed, yielding a fully saturated model. To test the mediation assumption, we calculated indirect effects. For better interpretability of our findings, we report standardized parameter estimates reflecting how many standard deviations a dependent variable changes per standard deviation increase in the predictor variable.

\section{Results}

Descriptively (see Table 1), our results indicated similar levels of achievement goals as what is typically observed in research on faculty goals (rather strong learning and performance goals, weaker work avoidance goals; e.g., Daumiller et al., 2019). Participants' attitudes towards the change from face-to-face to online teaching seemed to be more favorable than unfavorable, with higher means for perceived positive challenge and perceived usefulness than for perceived threat. 
Table 1

Descriptive Statistics and Bivariate Correlations

\begin{tabular}{|c|c|c|c|c|c|c|c|c|c|c|c|c|c|c|}
\hline & \multicolumn{5}{|c|}{ Descriptive statistics } & \multicolumn{9}{|c|}{ Bivariate correlations } \\
\hline & $N$ & M & $S D$ & Skew & Range & 1 & 2 & 3 & 4 & 5 & 6 & 7 & 8 & 9 \\
\hline \multicolumn{15}{|l|}{ Faculty achievement goals (T1) } \\
\hline 1 Learning approach & 80 & 6.92 & 1.16 & -1.95 & $1-8$ & & & & & & & & & \\
\hline 2 Performance (appearance) approach & 80 & 6.04 & 1.40 & -1.09 & $1-8$ & .38 & & & & & & & & \\
\hline 3 Performance (appearance) avoidance & 78 & 6.37 & 1.71 & -1.11 & $1-8$ & .36 & .71 & & & & & & & \\
\hline 4 Work avoidance & 78 & 3.00 & 1.89 & 0.79 & $1-8$ & -.20 & .24 & -.04 & & & & & & \\
\hline \multicolumn{15}{|c|}{ Faculty attitudes regarding the change to digital teaching (T2) } \\
\hline 5 Perceived threat & 36 & 2.51 & 1.36 & 2.11 & $1-8$ & .16 & .38 & .39 & .28 & & & & & \\
\hline 6 Perceived positive challenge & 36 & 5.28 & 1.27 & -0.06 & $2.3-8$ & .45 & .35 & .23 & .16 & .17 & & & & \\
\hline 7 Perceived usefulness & 36 & 5.18 & 1.71 & -0.58 & $1-8$ & .49 & .20 & .14 & .09 & .15 & .78 & & & \\
\hline \multicolumn{15}{|c|}{ Faculty experiences and student evaluations of teaching quality } \\
\hline 8 Burnout levels (T2) & 77 & 2.62 & 0.66 & 0.53 & $1.3-4.7$ & -.31 & .04 & -.03 & .34 & .55 & -.06 & -.06 & & \\
\hline $\begin{array}{l}9 \text { Student evaluations of teaching } \\
\text { quality (T3) }\end{array}$ & 40 & 2.86 & 0.24 & -0.61 & $2.3-3.3$ & .07 & -.05 & -.08 & .01 & -.17 & -.37 & -.26 & -.27 & \\
\hline \multicolumn{15}{|l|}{ Demographic variables (T1) } \\
\hline Gender $(1=$ female, $0=$ male $)$ & 79 & 0.42 & & & $0 ; 1$ & .06 & -.07 & -.01 & -.25 & .06 & .02 & .07 & -.22 & .13 \\
\hline Age (in years) & 80 & 38.28 & 10.01 & 0.98 & $24-65$ & -.08 & -.11 & -.04 & -.17 & -.15 & .06 & .03 & -.11 & -.07 \\
\hline Teaching experience (in years) & 80 & 9.86 & 8.05 & 1.12 & $1-36$ & -.18 & -.08 & -.09 & -.13 & -.07 & -.08 & -.07 & -.04 & -.06 \\
\hline $\mathrm{PhD}(1=$ yes, $0=$ no $)$ & 80 & 0.65 & & & $0 ; 1$ & -.22 & -.13 & -.09 & -.26 & -.17 & -.08 & -.10 & -.04 & .04 \\
\hline Full professor $(1=$ yes, $0=$ no $)$ & 80 & 0.10 & & & $0 ; 1$ & -.47 & -.29 & -.22 & -.04 & -.32 & -.35 & -.19 & .14 & -.31 \\
\hline
\end{tabular}

Both goals and attitudes varied considerably between the different participants of our study, which underscores that these constructs may be sensible for describing interindividual differences in motivations and attitudes of scholars. In line with prior research, we observed a strong correlation between performance approach and performance avoidance goals that points to the conceptual similarity of these two types of goals, while both nevertheless represent different constructs (half of their variance being shared, the other half unique; as also supported by the confirmatory factor analyses). We also found perceived positive challenge and perceived usefulness to be similarly related in terms of strength, which can be interpreted analogously. Given these findings, it makes sense to study the relations between these constructs in a comprehensive model where all types of goals and attitudes are considered simultaneously, as we did next.

Results of the path model (see Figure 2) indicated that perceiving the forced change to online teaching due to COVID-19 as a positive challenge was positively associated with participants' learning approach goals prior to the outbreak of the pandemic. Similarly, perceived usefulness was also positively, and descriptively quite strongly, related to participants' learning goals, but not to the other types of goals. Conversely, participants reported higher perceived threat the stronger their performance avoidance and work avoidance goals were before the COVID-19 outbreak. Regarding the subsequent outcome variables, we found that perceived threat positively predicted faculty burnout levels and negatively predicted their students' evaluations of teaching quality in terms of their learning. Contrary to our expectations, the other two attitudes were not statistically significantly related to these variables. Investigation of indirect effects showed that performance avoidance goals were related to burnout levels $(\beta=.17$; S.E. $=.09)$ and teaching quality $(\beta=-.25$; S.E. $=.11$ ) mediated through perceived threat (none of the other indirect effects reached statistical significance). To test the robustness of our findings, we excluded individual variables and compared our findings to the bivariate correlations, none of which provided indications for distortions such as suppressor effects.

\section{Discussion}

The COVID-19 pandemic put online teaching and learning under a stress-test that accelerated the digitalization of higher education teaching. In the present study, we focused on faculty members' motivations and attitudes towards this sudden shift to elucidate interindividual differences in how they experienced and dealt with this situation. Strengths of our study lie in 


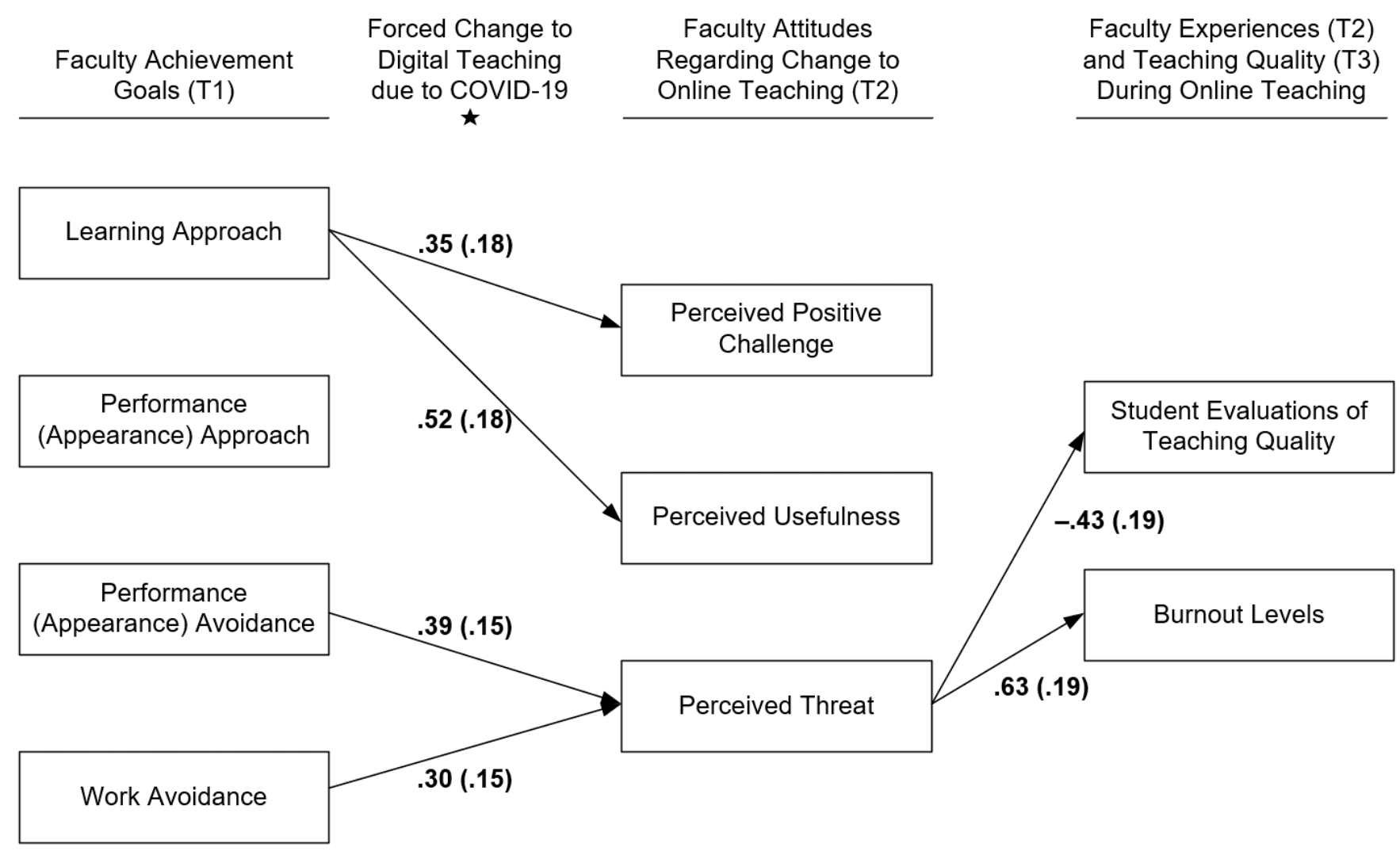

Figure 2. Statistically significant effects of the hypothesized paths. Parameter estimates for the non-significant paths are not presented for clarity but are reported in Table S1 in the supplemental materials. Presented are standardized parameters with their standard errors in brackets. Correlations between goals, between attitudes, and between the two outcome variables were modeled but are not presented.

the use of multiple measurement points (before and after the transition to online teaching), the inclusion of two sources to investigate the relevance of faculty attitudes (teacher and student reports), as well as the innovative consideration of achievement goals as personal predictors. Taken together, our findings largely supported our expectations and emphasize that achievement goals can be considered to underlie different attitudes towards the change to online teaching, which in turn, matter for interindividual differences in their burnout/engagement experiences as well as teaching quality during online teaching.

Regarding the linkages between achievement goals and attitudes towards the change to online teaching (H1a-d), our assumptions were largely supported by the data. Learning approach goals being associated with perceived positive challenge and usefulness for competence development aligns well with the orientation of this motivation towards personal growth and competence development. This also stresses the notion that faculty strongly pursuing such goals may be more likely to interpret the shift to online teaching as a positive learning experience. Additionally, this finding complements past research documenting positive associations between learning goals and help-seeking attitudes as well as professional learning (e.g., Daumiller, Rinas, et al., 2020; Hein et al., 2019; see also Payne et al., 2007) and implies that comparable attitudes may also be expected to underlie successful (informal) learning activities. Opposed to this, we did not find the expected statistically significant negative links between learning goals and perceived threat.

Performance avoidance and work avoidance goals were related to perceived threat resulting from the pandemic induced change to digital teaching, but not to perceived positive challenge and usefulness. These links with perceived threat are in line with our expectations that faculty pursuing performance avoidance goals should tend to perceive such situations as threatening, as they might worry about failing and not performing well. Work avoidance goals additionally being tied to perceived threat highlights that online teaching 
may generally entail unique challenges requiring resources (that may already be limited during COVID19) and effort put forth by faculty members to succeed at generating meaningful online learning experiences (see Rapanta et al., 2020).

Taken together, these findings imply that in order to elucidate interindividual differences in faculty members' attitudes towards the COVID-19 enforced change to online teaching, it seems relevant to consider all of the aforementioned goals. Focusing solely on learning approach goals might for instance not explain differences in perceived threat adequately. It is worth noting, however, that we did not find significant links for performance approach goals. This corresponds to the generally inconsistent findings regarding this type of goal for perceptions and behaviors (see Daumiller et al., 2019; Hulleman et al., 2010; Tanaka et al., 2002). To follow up on this, future research should consider moderators such as faculty members' perceptions of their own competence (see Ajzen, 1985). This could be particularly relevant as performance goals may only be linked to a situation being perceived as a positive challenge if faculty evaluate their own competences as sufficient enough to master the challenge, but not too high, as then it would not be a challenge in the first place.

Regarding the associations of attitudes towards this sudden change with burnout/engagement and student evaluations of teaching quality in terms of learning $(\mathrm{H} 2 \mathrm{a}-\mathrm{H} 2 \mathrm{~b})$, our expectations were only supported for perceived threat, but not the other two attitudes. These clear findings for perceived threat regarding the shift to online teaching reinforce our reasoning that such attitudes should be tied to increased concern, less successful coping, and limited resources - all of which can ultimately lead to increased burnout levels and hinder engagement as well as full use of the online teaching potential (e.g., passive instead of higher quality learning activities; Chi \& Wylie, 2014). As we found that perceived threat mediated the effects from performance avoidance goals on burnout/engagement and teaching quality, this speaks to our assumption of goals being relevant for different interpretations of achievement situations (such as the shift to online teaching and learning) that in turn matter for how individuals experience and handle it. Interestingly, we could not confirm the expected links of perceived positive challenge and perceived usefulness for competence development for these two outcome variables. Here, it might be the case that the effects for perceived threat are stronger or that these two attitudes matter more for other aspects such as actual learning activities of faculty members or their experiences of enjoyment during online teaching. Including further outcome variables can therefore be considered a relevant step for a more comprehensive picture of how these attitudes function. Another interesting research direction may entail studying the interplay between the different types of attitudes in more detail, for example, by investigating profiles of faculty members based on their attitudes (see Scherer et al., this special issue, for a similar approach regarding faculty members' readiness for online teaching and learning). Such an approach could, for instance, investigate the idea that perceived positive challenge or perceived usefulness alone may not be sufficient for better engagement, but only when paired with low perceived threat.

Interpreting these findings, it should be borne in mind that we considered burnout/engagement and student evaluations of teaching quality in terms of learning as two equal outcome variables regarding how faculty experience and handle the shift to online teaching. However, these two constructs likely also influence each other, as it may be difficult to achieve high teaching quality during this shift to online teaching in times of high burnout levels, while in turn, outspending oneself to achieve high teaching quality might increase burnout levels. While future research would profit from following up on this interplay in more detail, given the small association that we observed between these two constructs in the present study, we conclude that attitudes towards the sudden change to online teaching, particularly regarding perceived threat, seem to matter for both constructs. This confirms the basic premise of the present work and in particular, extends past research on the role of attitudes for technology adoption (e.g., Davis, 1985; Dwivedi et al., 2017; HernándezRamos et al., 2014; Venkatesh \& Davis, 2000), indicating that the aforementioned attitudes are also important for how faculty members experience and handle shifting from face-to-face to online teaching. Here, it must be considered that the effects of the attitudes might be particularly strong in the first semester of teaching online, and could become weaker over time as faculty get more accustomed to online teaching-future research should follow up on this by considering the development of the strength of these attitudes over time (see Nistor et al., 2019).

Aside from online teaching and learning, as well as technology use, our findings may also be interpreted in the light of how faculty deal with crises and unexpected challenges in general. As can be inferred from the COVID-19 outbreak, dealing with unexpected challenges is and will continue to be an issue that has important implications for university faculty members' 
well-being, professional learning, and teaching quality. Our findings emphasize the role of personal prerequisites for resilience, innovation, and change. These personal factors can in turn be fostered through an according organizational climate (e.g., Barach et al., 2020; Wang \& Degol, 2016). Against this background, COVID-19 should additionally be considered as a catalyst for university systems to better prepare faculty members not only for online teaching, but also for unexpected challenges in general, and to this end, invest further in proactive resilience initiatives (see also $\mathrm{Ra}-$ panta et al., 2020).

Despite the strengths of the present research, some limitations need to be acknowledged. First, as each variable was only included once, causal conclusions cannot be drawn from our analyses. In particular, we did not consider change in burnout/engagement, but only burnout/engagement levels during the shift to online teaching. As such, we do not know whether the linkages that we found for this variable pertain to changes in burnout/engagement during this situation or general differences between participants in their burnout/engagement levels. Related to this, achievement goals could have shifted from the first to the second measurement point, which is why we could have underestimated their relevance (with goals during the shift to online teaching being more strongly tied to attitudes therein than goals prior to the shift). Second, while the sample size was sufficient to test the proposed hypotheses (assuming medium effects, as indicated by our power analyses), it cannot be ruled out that we missed smaller effects due to the restricted sample size (e.g., for perceived positive challenge or perceived usefulness for competence development). Third, while not relevant for the interpretation of the associations that we studied in the present work (but for the interpretation of the mean levels), it should be considered that our sample likely underestimates the actual levels of negative attitudes towards and for dealing with the shift to online teaching. It can be expected that faculty members who are particularly struggling with this situation (also with regard to difficulties in their personal lives), may not have had the resources available to additionally participate in our study, which is why we likely underestimate the gravity of this shift in our work.

Finally, it should be borne in mind that we focused on achievement goals and attitudes towards the sudden change to online teaching as personal factors given their theoretical relevance as potential antecedents of faculty teaching experiences and student learning experiences during COVID-19. However, aside from these investigated variables, other personal aspects are also relevant and should be acknowledged, such as faculty members' skills regarding online teaching (see model by Sailer et al., this special issue, and Hofer et al., this special issue). In particular, lacking digital technology skills and experience can be a threat to many (especially older) faculty members: Despite adaptive motivations, these individuals might struggle with the shift to online teaching due to lacking skills. Moreover, not only personal but also contextual aspects at the university and administration level (e.g., educational support), matter and need to be considered for a comprehensive understanding of how best to facilitate successful online teaching and learning (Martin et al., 2020). Nevertheless, as many of the current research initiatives are already addressing the shift from face-to-face to online teaching and learning in terms of different skills and contexts, our findings offer valuable information towards the importance of particularly also considering faculty achievement goals and attitudes (especially as motivations also underlie faculty developing technological skills and deciding to use administrative support in the first place).

Despite our study being the first to investigate this topic, preliminary ideas concerning practical implications can already be derived. Specifically, it can be considered important to support faculty members in fostering learning approach goals and reducing perceived threat, which, in turn, can also be facilitated through the reduction of performance avoidance and work avoidance goals. This could potentially be achieved within the context of professional development courses aimed at improving faculty experiences with online teaching and learning or by supplementing courses or learning materials about online teaching skills. Therein, an emphasis could be placed on the relevance and importance of perceiving the online transition as a learning opportunity to develop knowledge and improve competencies. At the same time, faculty could be reminded that mistakes are a natural part of the learning process, and that resources exist to support them to succeed (prompting them to avoid resorting to maladaptive coping mechanisms such as orienting themselves towards avoiding tasks or putting forth minimal effort). Nevertheless, as only few studies thus far have examined the role of achievement goals in this novel context, further research is required to derive specific and thorough suggestions for practice.

\subsection{Conclusions}

COVID-19 temporarily sped up the transition to digital teaching, which allowed unparalleled insights 
into the role of computers for human behaviors, particularly regarding online teaching and learning. In principle, online teaching has the capacity to become as effective as face-to-face teaching (see, for example, Francescato et al., 2006). Within this, however, multiple requisites need to be ensured. Our findings highlight that aside from technological and contextual factors, personal, especially motivational, factors of faculty also play an important role, particularly their goals and attitudes towards this sudden change. We found these constructs to be intertwined with their burnout/engagement in the face of the pandemic, as well as their students' evaluations of teaching quality in terms of learning - underscoring their relevance for learning and performance in the transition to online teaching and learning. Given the right motivations and attitudes towards this sudden change, faculty may better handle such transitions and be equipped to acknowledge and perceive unexpected challenges such as the COVID-19 outbreak as opportunities instead of vexations.

\section{References}

Ahmed, A., \& Ikram Khan, A. (2020). Report on online teaching and learning amid COVID-19. https://papers.ssrn.com/sol3/papers.cfm?abstract_id=3646414

Ajzen, I. (1985). From intentions to actions: A theory of planned behavior. In J. Kuhl \& J. Beckmann (Eds.), Action control (pp. 11-39). Springer. https://doi.org/10.1007/978-3-642-69746-3_2

Albarracin, D., \& Shavitt, S. (2018). Attitudes and attitude change. Annual Review of Psychology, 69, 299-327. https://doi.org/10.1146/annurev-psych-122216-011911

Bardach, L., Oczlon, S., Pietschnig, J., \& Lüftenegger, M. (2019). Has achievement goal theory been right? A metaanalysis of the relation between goal structures and personal achievement goals. Journal of Educational Psychology, 112(6), 1197-1220. https://doi.org/10.1037/edu0000419

Besser, A., Lotem, S., \& Zeigler-Hill, V. (2020). Psychological stress and vocal symptoms among university professors in Israel: Implications of the shift to online synchronous teaching during the COVID-19 pandemic. Journal of Voice. Advanced online publication. https://doi.org/10.1016/j.jvoice.2020.05.028

Bhat, R., Singh, V. K., Naik, N., Kamath, C. R., Mulimani, P., \& Kulkarni, N. (2020). COVID 2019 outbreak: The disappointment in Indian teachers. Asian Journal of Psychiatry, 50, 102047. https://doi.org/10.1016/j.ajp.2020.102047

Brenninkmeijer, V., \& VanYperen, N. (2003). How to conduct research on burnout: Advantages and disadvantages of a unidimensional approach in burnout research. Occupational and Environmental Medicine, 60, 16-20. https://dx.doi.org/10.1136/oem.60.suppl_1.i16
Büssing A. \& Glaser J. (1998). Managerial stress and burnout. A collaborative international study (CISMS); The German investigation. TU Munich, Chair of Educational Psychology.

Butler, R. (2007). Teachers' achievement goal orientations and associations with teachers' help-seeking: Examination of a novel approach to teacher motivation. Journal of Educational Psychology, 99(2), 241-252. https://doi.org/10.1037/0022-0663.99.2.241

Butler, R. (2014). What teachers want to achieve and why it matters: An achievement goal approach to teacher motivation. In P. W. Richardson, S. A. Karabenick, \& H. M. G. Watt (Eds.), Teacher motivation: Theory and practice (pp. 20-35). Routledge.

Chen, I.-S. (2017). Work engagement and its antecedents and consequences: A case of lecturers teaching synchronous distance education courses. Computers in Human Behavior, 72 , 655-663. https://doi.org/10.1016/j.chb.2016.10.002

Chi, M. T., \& Wylie, R. (2014). The ICAP framework: Linking cognitive engagement to active learning outcomes. Educational Psychologist, 49(4), 219-243. https://doi.org/10.1080/00461520.2014.965823

Damşa \& Langford, this special issue

Daumiller, M., Dickhäuser, O., \& Dresel, M. (2019). University instructors' achievement goals for teaching. Journal of Educational Psychology, 111(1), 131-148. https://doi.org/10.1037/edu0000271

Daumiller, M., \& Dresel, M. (2018). Subjective perceptions of the teaching-research nexus and occupational stress at universities. Zeitschrift für Entwicklungspsychologie und Pädagogische Psychologie/German Journal of Developmental and Educational Psychology, 50(3), 126-138. https://doi.org/10/cwmt

Daumiller, M., \& Dresel, M. (2020). Researchers' achievement goals, work stress, and professional development: Results of three studies. Contemporary Educational Psychology, 61, 101843. Advanced online publication. https://doi.org/10.1016/j.cedpsych.2020.101843

Daumiller, M., Grassinger, R., Dickhäuser, O., \& Dresel, M. (2016). Structure and relationships of university instructors' achievement goals. Frontiers in Psychology, 7, 375. https://doi.org/10.3389/fpsyg.2016.00375

Daumiller, M., Grassinger, R., Engelschalk, T. \& Dresel, M. (2021). SEEQ-DE: Konstruktion und Überprüfung einer deutschsprachigen Adaption des Instruments „Student Evaluation of Educational Quality“ (Marsh). https://doi.org/10.31234/osf.io/ma3x9

Daumiller, M., Janke, S., Hein, J., Rinas, R., Dickhäuser, O., \& Dresel, M. (2021). Do teachers' achievement goals and self-efficacy beliefs matter for students' learning experiences? Evidence from two studies on perceived teaching quality and emotional experiences. https://doi.org/q0.31234/osf.io/5926v

Daumiller, M., Rinas, R., Olden, D., \& Dresel, M. (2020). Academics' motivations in professional training courses: 
Effects on learning engagement and learning gains. International Journal of Academic Development. Advanced online https://doi.org/10.1080/1360144X.2020.1768396

Daumiller, M., Stupnisky, S., \& Janke, S. (2020). Motivation of higher education faculty: Theoretical approaches, empirical evidence, and future directions [Editorial]. International Journal of Educational Research, 20. https://doi.org/10.1016/j.ijer.2019.101502

Davis, F. D. (1985). A technology acceptance model for empirically testing new end-user information systems: Theory and results [Doctoral dissertation, Massachusetts Institute of Technology].

Dickhäuser, O., Butler, R., \& Tönjes, B. (2007). Das zeigt doch nur, dass ich's nicht kann [That only shows that I can't do it]. Zeitschrift für Entwicklungspsychologie und Pädagogische Psychologie, 39(3), 120-126. https://doi.org/10.1026/0049-8637.39.3.120

Dwivedi, Y. K., Rana, N. P., Jeyaraj, A., Clement, M., \& Williams, M. D. (2019). Re-examining the unified theory of acceptance and use of technology (UTAUT): Towards a revised theoretical model. Information Systems Frontiers, 21(3), 719-734. https://doi.org/10.1007/s10796017-9774-y

Enders, C. K., \& Bandalos, D. L. (2001). The relative performance of full information maximum likelihood estimation for missing data in structural equation models. Structural Equation Modeling, 8, 430-457. https://doi.org/10.1207/S15328007SEM0803_5

Folkman, S., Lazarus, R. S., Dunkel-Schetter, C., DeLongis, A., \& Gruen, R. J. (1986). Dynamics of a stressful encounter: Cognitive appraisal, coping, and encounter outcomes. Journal of Personality and Social Psychology, 50(5), 992-1003.

Francescato, D., Porcelli, R., Mebane, M., Cuddetta, M., Klobas, J., \& Renzi, P. (2006). Evaluation of the efficacy of collaborative learning in face-to-face and computersupported university contexts. Computers in Human Behavior, 22(2), 163-176. https://doi.org/10.1016/j.chb.2005.03.001

Freudenberger, H. J. (1974). Staff burn-out. Journal of Social Issues, 30(1), 159-165. https://doi.org/10.1111/j.1540-4560.1974.tb00706.x

Gorozidis, G., \& Papaioannou, A. (2011). Teachers' self-efficacy, achievement goals, attitudes and intentions to implement the new Greek physical education curriculum. European Physical Education Review, 17(2), 231-253. https://doi.org/10.1177/1356336X11413654

Granziera, H., Collie, R., Martin, A. (2021) Understanding teacher wellbeing through Job Demands-Resources Theory. In C. Mansfield (Ed.), Cultivating Teacher Resilience (pp. 229-244). Springer. https://doi.org/10.1007/978-981-15-5963-1_14

Hernández-Ramos, J. P., Martínez-Abad, F., García Peñalvo, F. J., Esperanza Herrera García, M., \& Rodríguez-Conde, M. J. (2014). Teachers' attitude regarding the use of ICT.
A factor reliability and validity study. Computers in $\mathrm{Hu}$ man Behavior, 31, 509-516. https://doi.org/10.1016/j.chb.2013.04.039

Hein, J., Daumiller, M., Janke, S., Dresel, M., \& Dickhäuser, O. (2019). How learning time mediates the impact of university scholars' learning goals on professional learning in research and teaching. Learning and Individual Differences, $\quad 72, \quad 15-25 . \quad$ https://doi.org/10.1016/j.lindif.2019.04.002

Hofer, S., Nistor, N., Scheibenzuber, C. (2020). Online teaching and learning in higher education: Lessons learned in crisis situations. Computers and Human Behavior [this special issue]

Huet, N., Escribe, C., Dupeyrat, C., \& Sakdavong, J.-C. (2011). The influence of achievement goals and perceptions of online help on its actual use in an interactive learning environment. Computers in Human Behavior, 27(1), 413-420. https://doi.org/10.1016/j.chb.2010.09.003

Hulleman, C. S., Schrager, S. M., Bodmann, S. M., \& Harackiewicz, J. M. (2010). A meta-analytic review of achievement goal measures. Psychological Bulletin, 136(3), 422-449. https://doi.org/10.1037/a0018947

Karabenick, S. A. (2004). Perceived achievement goal structure and college student help seeking. Journal of Educational Psychology, 96(3), 569-581. https://doi.org/10.1037/0022-0663.96.3.569

Krischler, M., \& Pit-ten Cate, I. (2019). Pre- and in-service teachers' attitudes toward students with learning difficulties and challenging behavior. Frontiers in Psychology, 10(327). https://doi.org/10.3389/fpsyg.2019.00327

Linnenbrink, E. A. (2005). The dilemma of performance-approach goals: The use of multiple goal contexts to promote students' motivation and learning. Journal of Educational Psychology, 97(2), 197-213. https://doi.org/10.1037/0022-0663.97.2.197

Little, T. D., Lang, K. M., Wu, W., \& Rhemtulla, M. (2016). Missing Data. Developmental Psychopathology, 1, 1-37. https://doi.org/10.1002/9781119125556.devpsy117

Lohr et al., this special issue

Kim, J., \& Maloney, E. (2020). Learning Innovation and the Future of Higher Education. JHU Press.

Marsh, H. W. (1982). SEEQ: A reliable, valid and useful instrument for collecting students' evaluations of university teaching. British Journal of Educational Psychology, 52(1), 77-95. https://doi.org/10.1111/j.20448279.1982.tb02505.x

Marsh, H. W. (2007). Students' evaluations of university teaching: Dimensionality, reliability, validity, potential biases and usefulness. In R. P. Perry \& J. C. Smart (Eds.), The scholarship of teaching and learning in higher education: An evidence-based perspective (pp. 319-383). Springer. https://doi.org/10.1037/0022-0663.76.5.707

Martin, F., Sun, T., \& Westine, C. (2020). A systematic review of research on online teaching and learning from 2009 to 2018. Computers \& Education, 159, 104009. https://doi.org/10.1016/j.compedu.2020.104009 
Maslach, C., \& Leiter, M. P. (2008). Early predictors of job burnout and engagement. Journal of Applied Psychology, 93(3), 498-512. https://doi.org/10.1037/00219010.93.3.498

Maslach, C., Jackson, S. E., \& Leiter, M. P. (1996). Maslach Burnout Inventory Manual (3rd ed.). Consulting Psychologists Press.

Muthén, L., \& Muthén, B. (2018). Mplus (version 8.1) [Computer Software]. Muthén \& Muthén.

Nistor, N., Stanciu, D., Lerche, T., \& Kiel, E. (2019). "I am fine with any technology, as long as it doesn't make trouble, so that I can concentrate on my study": A case study of university students' attitude strength related to educational technology acceptance. British Journal of Educational Technology, 50(5), 2557-2571. https://doi.org/10.1111/bjet.12832

Nistor, N., Wagner, M., Istvanffy, E., \& Dragota, M. (2010). The Unified Theory of Acceptance and Use of Technology: Verifying the model from a European perspective. International Journal of Knowledge and Learning, 6(23), 185-199. https://doi.org/10.1504/IJKL.2010.034753

Offir, B., Lev, Y., \& Bezalel, R. (2008). Surface and deep learning processes in distance education: Synchronous versus asynchronous systems. Computers \& Education, $51(3)$, https://doi.org/10.1016/j.compedu.2007.10.009

Ortiz P. A. (2020). Teaching in the time of COVID-19. Biochemistry and Molecular Biology Education, 48(3), 201. https://doi.org/10.1002/bmb.21348

Payne, S. C., Youngcourt, S. S., \& Beaubien, J. M. (2007). A meta-analytic examination of the goal orientation nomological net. Journal of Applied Psychology, 92(1), 128-150. https://doi.org/10.1037/0021-9010.92.1.128

Peugh, J. L., \& Enders, C. K. (2004). Missing data in educational research: A review of reporting practices and suggestions for improvement. Review of Educational Research, 74(4), 525-556. https://doi.org/10.3102/00346543074004525

Rapanta, C., Botturi, L., Goodyear, P., Guàrdia, L., \& Koole, M. (2020). Online university teaching during and after the Covid-19 crisis: Refocusing teacher presence and learning activity. Postdigital Science and Education, 123. https://doi.org/10.1007/s42438-020-00155-y

Reinhold et al., this special issue

Ryan, A. M., \& Pintrich, P. R. (1997). "Should I ask for help?" The role of motivation and attitudes in adolescents' help seeking in math class. Journal of Educational Psychology, 89(2), 329-341. https://doi.org/10.1037/0022-0663.89.2.329

Sabagh, Z., Hall, N. C., \& Saroyan, A. (2018). Antecedents, correlates, and consequences of faculty burnout. Educational Research, 1-26. https://doi.org/10.1080/00131881.2018.1461573

Sailer, Schultz-Pernice, \& Fischer, this special issue

Sălceanu, C. (2020). Higher Education challenges during Covid-19 pandemic. A case study. Revista Universitară de Sociologie, 104(1), 104-124.
Scherer et al., this special issue

Schwarzer, R., \& Jerusalem, M. (1999). Skalen zur Erfassung von Lehrer-und Schülermerkmalen [Scales for the assessment of teacher and student characteristics]. https://www.psyc.de/skalendoku.pdf

Schwarzer, R., \& Jerusalem, M. (1995). Generalized SelfEfficacy scale. In J. Weinman, S. Wright, \& M. Johnston (Eds.), Measures in health psychology: A user's portfolio. Causal and control beliefs (pp. 35-37). NFER-NELSON.

Skaalvik, S., \& Skaalvik, E. M. (2005). Self-concept, motivational orientation, and help-seeking behavior in mathematics: A study of adults returning to high school. Social Psychology of Education, 8(3), 285-302. https://doi.org/10.1007/s11218-005-3276-3

Tanaka, A., Murakami, Y., Okuno, T., \& Yamauchi, H. (2002). Achievement goals, attitudes toward help seeking, and help-seeking behavior in the classroom. Learning and Individual Differences, 13(1), 23-35. https://doi.org/10.1016/S1041-6080(02)00043-2

UNESCO (2020, March 13). COVID-19 educational disruption and response. UNESCO. https://en.unesco.org/themes/education-emergencies/coronavirus-school-closures

Venkatesh, V., \& Davis, F. D. (2000). A theoretical extension of the technology acceptance model: Four longitudinal field studies. Management Science, 46(2), 186-204. https://doi.org/10.1287/mnsc.46.2.186.11926

Venkatesh, V., Morris, M. G., Davis, G. B., \& Davis, F. D. (2003). User acceptance of information technology: Toward a unified view. MIS Quarterly, 27(3), 425-478. https://doi.org/10.2307/30036540

Wang, M. T., \& Degol, J. L. (2016). School climate: A review of the construct, measurement, and impact on student outcomes. Educational Psychology Review, 28(2), 315-352. https://doi.org/10.1007/s10648-015-9319-1

Wekerle, C., Daumiller, M., \& Kollar, I. (2020). Using digital technology to promote higher education learning: The importance of different learning activities and their relations to learning outcomes. Journal of Research on Technology in Education. Advanced online publication. https://doi.org/10.1080/15391523.2020.1799455

Zahavi, H., \& Friedman, Y. (2019). The Bologna Process: An international higher education regime. European Journal of Higher Education, 9(1), 23-39. https://doi.org/10.1080/21568235.2018.1561314

\footnotetext{
Note. This is a pre-copyedited, author-produced PDF of an article accepted for publication in Computers in Human Behavior following peer review. This paper is not the copy of record and may not exactly replicate the final, authoritative version of the article. The final article will be available, upon publication, via its DOI.
} 


\section{Footnotes}

${ }^{1}$ Beyond the aforementioned types of goals, further sets of goals and differentiations have been proposed (see Daumiller et al., 2019, for an overview), however, these were not investigated in the present study due to their lack of congruence with our research questions. In line with this reasoning, we also exclusively focused on the appearance aspect of performance goals as opposed to the normative aspect. As the normative aspect entails a focus on outperforming others, we expected this to be difficult for faculty members to track and compare during online teaching and as such, did not consider it to be a relevant motivational driver regarding the scope of our study.

${ }^{2}$ In the German higher education system, there are many faculty members without PhDs that teach classes. These often include graduate students pursuing $\mathrm{PhDs}$ who usually have a master's degree already and are typically part of the academic staff (having at least a half-time contract as a faculty member entailing teaching responsibilities; see Daumiller et al., 2019, for a more detailed description). We additionally considered faculty rank (faculty member without $\mathrm{PhD}$ : yes or no; full professor: yes or no) and whether or not participants were tenured as a control variable. This did not result in different findings.

${ }^{3}$ Prior experience with online teaching was not statistically significantly associated with any of the variables relevant for our research questions.

${ }^{4}$ We also assessed the other goal types distinguished by Daumiller et al. (2019) in their overview model (task goals, learning avoidance goals, performance normative goals, relational goals). As they were not relevant for the present investigation and we had no hypotheses for them, we do not report on them further. 